\title{
The Influence of Sensory Marketing: a Study of Atmospheric Factors and Consumer Response
}

\author{
Laimona Sliburyte ${ }^{1}$, Jérémy Le $\mathrm{Ny}^{2}$ \\ ${ }^{1,2}$ Department of Marketing, Kaunas University of Technology, Kaunas, Lithuania \\ E-mails: ${ }^{l}$ laimona.sliburyte@ktu.lt (corresponding author); ${ }^{2}$ jeremy.le@ktu.edu
}

Received 13 February 2017; accepted 11 April 2017

\begin{abstract}
This paper focuses on the sensory marketing that wants to be a marketing tool which influences the mood and consumer behavior. The consumer is not looking only for buying a product or a service alone, but he is seeking an emotional and unique experience around what he buys. In line with previous studies, our survey study reveals how consumers evaluated the atmosphere of restaurants through the cognitive and emotional reactions. A synergy makes the internal response (cognitive and/or emotional) of the customer-facing the stimuli of the atmosphere, superposition of the four senses (sound, sight, touch, smell). According to our survey results, this research highlights the importance of recognizing that the stimuli of the atmosphere of the point of sales influence to emotional (feel more pleasure) and cognitive (perceive a better quality) responses of the customer through the experience of the sensory marketing.
\end{abstract}

Keywords: sensory marketing, atmosphere at the point of sale, atmospheric factors, consumer response, cognitive response, emotional response.

JEL Classification: M30, M31.

Conference topic: Modern Business Management Problems and Perspectives.

\section{Introduction}

The economic context of these days encourages the companies to invest in the sensory marketing. During a long time, human senses have been ignored, or at least considered as a different field than the marketing. It is through the five senses that each person perceives his environment. The knowledge about the senses of the person might make the marketing strategy of a company more successful and the sensory experience of the customer more personalized. The main reason for the brands to develop the sensory marketing is to be differentiated on the actual or targeted market. For a long time, the brands have worked mainly in the visual sense, through the color codes, the design, or the logos (Dosquet 2015). Therefore, the sensory marketing has been used to offer a unique experience to the customer. Daucé and Rieunier (2002) defined it as the fact to use the factors of the atmosphere of the point of sale in order to arouse affective, cognitive and behavioral reactions of the customers encouraging the purchase acts. These authors defined the factors composing the atmosphere of the selling points as the tactile factors (the materials, the temperature, etc.), the gustatory factors, the olfactory factors (the ambient scents, the smell of the products, etc.), the visual factors (the colours, the lights, the design, etc.), the hearing factors (the music in the background, the ambient sounds), and the social factors (the category of customers, the category of sellers, etc.). The sensory marketing is a part of the marketing which wants to be closer to the customer by appealing to the unconsciousness of the human being, which means the feelings, the memory, the perception and the emotions, which are private parts of each person. The sensory marketing wants to be a marketing tool which influences the mood and the behavior of the customers. Each reacts in different ways to the stimuli of the atmosphere at the point of sale, and then, perceives it in various ways.

It is a real challenge for the companies to gather all consumers in one entity with one sound, one touch, etc. However, several studies have shown the positive influence of the sensory stimuli on the mood and consumer behaviour, such as Schiffman et al. (1995), and later Villemure et al. (2003) who proved by an experiment, that a pleasant fragrance improve the mood and even can calm some symptoms such as unpleasant physical conditions. Through the time, the role of the customer in business and marketing process has changed: he passed from an individual almost without opinion, to the part of the business process, with feelings, heart, brain and emotions. He can feel and perceive. It is the gap between the perception and the sensation that makes the strength of the sensory marketing. Understanding the action from perception to mood is the proof that the mood affects the cognition and the emotion of customers.

(C) 2017 L. Sliburyte, J. Le Ny. Published by VGTU Press. This is an open-access article distributed under the terms of the Creative Commons Attribution (CC BY 4.0) License, which permits unrestricted use, distribution, and reproduction in any medium, provided the original author and source are credited. 
The sensory marketing, more than just bringing a service, also brings a personalized experience to the customer. The sensory marketing is then a marketing tool, using the senses of the consumer, which mean the tactile, visual, auditory, olfactory and gustatory senses (Rieunier 2006). The olfactory sense (smell) and the auditory sense (sound) are newer than the taste and the touch, which are both part of the traditional marketing. The sensory marketing appeared with the appearance of the smell and the sound in the marketing process. The principle of the sensory marketing is based on the value of one or more of the five senses of the human being (the sight, the hearing, the taste, the touch and the smell), which would allow companies to encourage the purchasing process while meeting the consumer expectations.

The main question about the consumer behavior is: why this store sells more than another one with the same products? The answer is because of the experience that the store can offer to customers. The consumers are ready to pay to live a pleasant experience. The sensory marketing can be defined, according to Rieunier and Jallais (2013) as the fact to use the ambient factors which surround the selling point (such as the music, the scent, the colour, the touching and tasting sensations) in order to stimulate, in the consumer's mind, a favourable reaction toward the purchasing act. Indeed, the environmental psychology is the study of the attitudes, perceptions, representations and accompanying behavior linked with the physical and social context in which the individual or group of individuals evolves (Moch, Moser 1997). This field has shown, since the beginning of the last century, that the environment, atmosphere surrounding the individual, can create an impact on his mood and his relaxation (emotional responses), on his thoughts (cognitive responses), and on his physical attitudes (behavioural responses), with experiments such as the theory of hierarchy of needs of Maslow et al. (1970). There is lack of generalized material, where the information about the influence of sensory marketing usage on consumer response would be stated systematically, and this allows formulating the research problem in a question - how does sensory marketing through the atmosphere (of the point of sales) influence the consumer response? The objective of the paper is to explore the influence of sensory marketing through the atmosphere (of the point of sales) on the consumer response.

\section{Theoretical background and hypotheses}

The goal of the sensory marketing is to seduce the customer, while increasing his well-being, in order to influence his behavior in a positive way concerning one product, or service, or a selling point (Daucé, Rieunier 2002). The perception of the significance of the senses in the marketing and the business, in general, has a valuable advantage in the market today. The sensory marketing is a useful tool which can provide, for the companies, an opportunity to increase the product profitability. The food industry has already used the potential of the sensory marketing partially: many restaurants, pubs or even bakeries try to exalt and stimulate the different senses by artificial systems (the artificial smell of fresh bread, for example). According to Lindström (2005), considering the senses of the human being can ensure a customer's experience in the store and can stimulate the imagination, improve the products and keep the customers through the loyalty. Creating a sensory brand starts from providing a personalized stimulus which can be linked to the brand.

Moreover, what Lindström (2010) basic point is that a brand which uses the multiple senses will be more successful than the ones which would focus on only a few senses (one or two). It can be a part of the advertising of the brand, such as a colour (for example the red of Coca-Cola, or the blue of Pepsi), logo, slogan, etc. or it can be a part of the product itself, such as shape of the product (Lamborghini cars' shapes), smell (perfumes) or taste of the product (Nutella).

Today, the marketers have understood the place of the senses in the marketing process and the customer buying process. The more senses a brand appeal to, the stronger would be the message, and the stronger would be the internal response (positive or negative). Several researchers such as Daucé and Rieunier (2002), Krishna (2012), based on the studies of Kotler (1973), have focused on a specific branch of the sensory marketing: the atmosphere of the point of sales.

From the theoretical review, we can point out that the senses of individuals, the way they perceive and feel the atmosphere of the point of purchases, are stimulated by what Daucé and Rieunier (2002) called the "atmospheric factors". The synergy between the perception and the sensation is, in one way, that can define the sensory marketing field (Krishna 2009). After the sensory organs are stimulated, the brain of the individual will create an internal response, according to the way and the context he perceives these stimuli. The internal response is characterized by emotional and/or cognitive reactions which create a positive or negative positioning of individual towards the brand or the product (Krishna 2012). This positioning is important because it defines the positive or negative reaction that would follow the individual (avoidance or approaching reaction) (Mehrabian, Russel 1974).

Indeed, the atmospheric factors come right out from the research of Daucé and Rieunier (2002) concerning the atmosphere of the selling point. They described the atmospheric factors as the scent, vision, sound and touch, and integrated all these factors in the sensory marketing process. Moreover, Yoo, Park, and MacInnis (1998) defined the atmosphere as a set of visual, olfactory and hearing effects. These atmospheric factors stimulate the sensory organs. The sensations (what the consumer feels through his sensory organs) and the perceptions (transmission, analysis, and interpretation of sensation by the brain) derived from this stimulation are transmitted to the brain which analyses and 
translates them in order to produce an internal response of the individuals (Bitner 1992; Krishna 2012). According to Krishna (2012), the internal response is divided into two parts: the cognitive reaction (which can have an influence on the perception of the quality) and the emotional reaction (which can have an influence on the customer pleasure). To quote once again Krishna (2012), the sensory marketing is 'marketing that engages the consumers' senses and affects their perception, judgment, and behavior" (Krishna 2012: 333). Indeed, the atmospheric factors are the vectors of the internal responses of customers. These stimuli would affect judgment, behavior, attitude, and even the experience they can have at the point of sale towards the pleasure the customers feel at the point of sales and the quality they perceive it.

According to the theories concerning the sensory marketing and especially the role of the atmosphere at the point of sales on the internal response of consumers and the analysis and the results found by the researchers in the past studies, as well as the previous frameworks (Mehrabian, Russell 1974; Bitner 1992; Yalch, Spangenberg 2000; Lindström 2005; Krishna 2012), some hypotheses were derived.

First of all, the sensory marketing has an impact on the consumer behavior, and in particular on the willingness of purchase state of consumer. As Daucé and Rieunier (2002) argued, the atmosphere at the point of sales can totally change the attitude of the customers. Some experiments made by researchers such as Hui, Dube, and Chebat (1997), showed that the atmospheric factors, and especially the music, can have a positive impact on the mood of behavior. The music and sounds, in general, can stimulate the pleasure and the memory of individuals, which probably can result in a desire to buy more, or at least to spend more time at the point of sales. The smell has a huge impact on the memory by touching the emotions that the customers have had an experience (pleasant or unpleasant). The researchers discuss about sensory memory (Lindstöm 2005). The smell can induce a relaxing feeling or can arouse a desire from the sensory memory. In general, according to the previous studies, all researchers from the sensory marketing field agreed that the atmosphere (and the sensory marketing in general) influences the behavior and the perceptions of the consumers. Krishna (2012) raised the fact that the stimulation of the customer by the atmosphere induces two categories of internal response: the cognitive reaction, and the emotional reaction.

The emotional reaction can be defined by the pleasure and the satisfaction felt by the customer through the stimulation of his sensory organs, while the cognitive reaction rather falls into the topic of the quality perceived by the customer. Through the management of the atmosphere at the selling point, the brand often tries to increase the pleasure, the well-being and stimulation of the customer (Rieunier, Daucé 2002). According to Bitner (1992) model two factors have a role in the emotional reaction of individuals: the mood and the attitude. Bitner (1992) defines the environment as the set of the tangible or intangible stimuli which influence the perception and the reaction of individuals. The interaction among these stimuli creates a global atmosphere which would create an effective reaction in customer's brain. Indeed, Mehrabian and Russell (1974) defined the emotional state as being a reaction that the individuals show while facing to the environment. The emotional response of employees and customers follows the PAD concept (Pleasure, Arousal, and Domination) developed by Mehrabian and Russell (1974) to describe and measure the emotional states according to the atmosphere and the environment. Several studies have explored the effects of a specific dimension on the emotional reaction of the customers. Lemoine (2002) showed that the light influences the pleasure and the stimulation of customer at the point of sale. The customers feel more dynamics and more nervous when facing to the unpleasant light while a pleasant lighting would involve a significant effect on the degree of happiness of the individual while visiting at the point of sale. Several studies, in particular on the ambient music (Alpert, M., Alpert, J. 1989; Bruner 1990), have proved that the factors of the atmosphere can influence the mood of individuals. The results of these studies showed that a store can influence the mood of customer by broadcasting different, dynamic and rhythmic music (Alpert, M., Alpert, J. 1989). These results highlighted as well that the management of the music could influence the pleasure felt by the customer (Sibéril 1994). When the music broadcasted is pleasant for customers, then, they are in a better mood (positive mood). Otherwise, the diffusion of the ambient scent has, as well, an impact on the pleasure felt by customers at the selling point: some pleasant smells bring a favourable effective response, while if the customer faces to the unpleasant smell, he can feel dissatisfaction and deterioration of his mood (Rieunier, Daucé 2002). Adopting the atmosphere in a holistic way, Lemoine (2002) has shown that the pleasure felt by the customer at the point of sale and his stimulation state are influenced by the social environment and design environment. The studies in psychology and sensory marketing fields have proved that the individuals react in a physiological way to the environmental stimuli: it can appear through increasing the heart rate, sweating of the skin or even increasing muscle tension (Rieunier, Daucé 2002). Researcher Lemoine (2002) showed that combination of the music, lighting and layout of the store could have a positive impact on satisfaction of customer, his degree of gladness and his entertainment. The association between the music and helpfulness of the staff would have an impact on the relaxation and calmness of consumer, and on his ability to feel full of energy. After conducting our literature review we derived two hypotheses:

H1: The consumers feel more pleasure (emotional reaction) of the point of sales when the atmospheric factors stimulate their senses.

$\mathrm{H} 2$ : The consumers perceive a better quality (cognitive) of the point of sales when the atmospheric factors stimulate their senses. 


\section{Research design}

The objective of the paper was to explore how sensory marketing through the atmosphere (of the point of sales) impacts on the consumer response. The methodological groundwork of the empirical study was formed of scientific studies analysis in sensory marketing (Kareklas et al. 2014; Labrecque et al. 2013; Krishna 2012; Krishna, Elder 2009; Balaji et al. 2011; Hulten 2011; Lindstrom 2010).

Usually, there are two main groups for a research method: quantitative and qualitative. These two terms are widely used in business studies (in general) to make the difference between data collection techniques and data analysis procedure (Saunders et al. 2003. According to Saunders et al. (2003), the qualitative data are presented as being non quantified and non numerical. The main objective is to collect information due to observations and discussions of the studied subject. A qualitative approach helps to measure a quite small sample of views of individuals (customers) or companies or products, etc. and to collect information in depth, by exploring feelings, motivations, thoughts, purchase behaviour, etc. The quantitative techniques are mainly used to specify the causality, usually between two or more variables. The qualitative method searches statistic results to point out the trends or frequencies. The objective is to standardise the data by collecting numerical information (Saunders et al. 2003), and to develop and use mathematical models, theories and/or hypothesis related to phenomena.

According to these facts, the primary data was collected through the questionnaire method (quantitative method). Indeed, the questionnaire has the objective of observing, measuring, decoding, understanding and interpreting the behaviour and opinions of the studied population or the studied sample, by comparing and quantifying them, to have a statistical inference. This method appears to be the most efficient for this research to have an overall perspective on the role of the atmosphere on the consumer response. For practical reasons, it has been decided in this case to focus the research on the use of the atmosphere in the restaurants in Lithuania. Indeed, more or less every individual has attended, at least one time some restaurant. Furthermore, the restaurants implement different atmospheres to attract the customers. It appears to be one of the places the most efficient to realise the empirical research. The choice of Lithuania as location of the research has been chosen for practical reasons of the research control. Quantitative research was chosen for the validation of hypotheses, and primary data were collected using a survey (research instrument - thirty-four questions questionnaire) method, non-random convenience sample. The survey questions were based on results of previous scientific research.

The reliability of the used instrument was assessed with the help of the Cronbach's alpha coefficient, which measures the internal consistency of the questionnaire scale. The questionnaire was reliable (Cronbach's alpha coefficient is 0.986), and it could be used for research. It has been decided to focus the research on the use of the atmosphere in the restaurants in Lithuania. The questionnaire was developed and transmitted to the respondents through the internet network. More specifically, the design of the questionnaire was made through the tool "Google Form" and sent via the social networks communities; therefore, it can be characterized as "e-questionnaire". We were able to formulate more objective conclusions appealing to the data collected through this way because there was no influence of the researcher to respondents. The study is based on a survey of 327 consumers $(\mathrm{N}=203$ men and $\mathrm{N}=124$ women) from Lithuania.

The data analysis is crucial for the research because it offers the chance to analyse, to interpret and to verify the theoretical studies done by the different researchers. Usually, the selection of the tool to analyse the data depends on the type of data collection such as quantitative or qualitative approaches. For examining the quantitative data collected through the questionnaire, it has been used SPSS software (Statistical Package for the Social Sciences): IBM SPSS Statistics 23.0. Through this tool, it has been created and developed different crosstabs or tables (such as frequency tables), in order to analyse and to answer to the main question of this research: how does the sensory marketing through the atmosphere (of the point of sale) impact the consumer response (cognitive and emotional reaction)?

Following statistical methods were used for the data analysis: the descriptive statistics (frequencies) were used to describe and discuss the characteristics of the sample; to explore the relationship between the variables, the nonparametric statistical technique was used (Chi-Square Test), and to know the strength of these relationships, the symmetric measures, and especially the Phi coefficients, were used.

\section{Results}

\section{The emotional reaction (pleasure) facing to the atmospheric cues}

The atmosphere, as described by Kotler (1973), Daucé and Rieunier (2002), Krishna (2012), has an influence on the emotional response of the consumer which would be translated through the attitude or the behavior of the consumers.

To go deeper, it has been analyzed if a relationship existed between the main factor the respondents are sensitive to while entering in a restaurant, and the pleasure they feel because of the atmosphere. Therefore, we can set two hypotheses h0 and h1:

$-\mathrm{h} 0$ : there is not any relationship between the proportion of respondents who feel pleasure through the atmosphere and the factors they are sensitive to while entering in a restaurant. 
$-\mathrm{h} 1$ : there is a relationship between the proportion of respondents who feel pleasure through the atmosphere and the factors they are sensitive to while entering in a restaurant. In other words, the pleasure felt through the atmosphere depends on the fact that the atmosphere stimulates them while entering into a restaurant, and thus that the pleasure is the cause that the atmosphere stimulates the respondent to enter the restaurant.

Table 1. Chi-Square test of the main sensitive factor while entering a restaurant and the fact that the pleasure is caused by the atmosphere in the restaurant (Source: composed by the authors)

\begin{tabular}{l|c|c|c}
\hline \multicolumn{1}{c|}{ Chi-Square test } & Value & df & Asymptotic Significance (2-sided) \\
\hline Pearson Chi-Square & $18,298^{\mathrm{a}}$ & 8 &, 019 \\
Likelihood Ratio & 21,031 & 8 &, 007 \\
Linear-by-Linear Association &, 618 & 1 &, 432, \\
N of Valid Cases & 327 & & \\
\hline
\end{tabular}

a. 4 cells $(26,7 \%)$ have expected count less than 5 . The minimum expected count is 1,14 .

The Chi-square test allows understanding if there is a significant link between the two variables "main sensitive factor" and "pleasure caused by atmosphere". The value of the Chi-Square is about 18.298 and the asymptotic significance $(=p)$ about 0.019 (see Table 1$)$. The p-value being less than 0.05 (the value of the statistical signification), we can reject h0 and we can confirm h1: there is a significant relationship between what respondents choose as main factors and their answer about the pleasure caused by the atmosphere. We can then deduce that there is a link between the fact that the atmosphere attracts them in the restaurant and the fact that they feel pleasure inside because of it. The association measures (Phi and Cramer's V) indicate the strength of the relationship between the two variables. The Phi statistic has a value of 0.237 (out of a maximum value of 1) which means that the relationship between these two variables has a medium strength. Therefore, the relationship between the main factor the respondents are sensitive to and the variable "pleasure caused by the atmosphere" is significant, but with a medium strength. Thus our H1 hypothesis: The consumers feel more pleasure when the atmospheric factors stimulate their senses was validated.

\section{The cognitive reaction (quality) facing to the atmospheric cues}

If the customer is not able to evaluate the intrinsic quality of the products or is not able to refer to his past experiences with the product or the brand, he realizes what is called "inferences" from the extrinsic assets of the product, it means the atmosphere. In other words, the customer uses the atmospheric information to evaluate the product (for example the quality of it).

With the same objective as previously, a Chi-Square test has been used to understand if a relationship existed between the variable "main sensitive factor" and the fact that the atmosphere affects the perception of the quality. For the well-being of this test, the variable "atmosphere perception quality" has been re-coded.

Table 2. Chi-Square test of the main sensitive factor while entering in a restaurant and the fact that the atmosphere affects the perception of the quality (Source: composed by the authors)

\begin{tabular}{l|c|c|c}
\hline \multicolumn{1}{c|}{ Chi-Square test } & Value & df & Asymptotic Significance (2-sided) \\
\hline Pearson Chi-Square & $8,128^{\mathrm{a}}$ & 8 &, 042 \\
Likelihood Ratio & 8,934 & 8 &, 348 \\
Linear-by-Linear Association & 3,778 & 1 &, 052 \\
N of Valid Cases & 327 & & \\
\hline
\end{tabular}

a. 10 cells $(66,7 \%)$ have expected count less than 5 . The minimum expected count is, 07 .

The Chi-square test allows understanding if there is a significant link between the two variables "main sensitive factor" and "quality caused by atmosphere". The value of the Chi-Square is about 8.128 and the asymptotic significance $(=p)$ about 0.042 (see Table 2 ). The p-value being less than 0.05 (the value of the statistical signification), we can reject h0 and we can confirm hl: there is a significant relationship between what respondents choose as main factors and their answer about the quality caused by the atmosphere. We can then deduce that a link exists between the fact that the atmosphere attracts them in the restaurant and the fact that they perceive better quality because of it. The association measures (Phi and Cramer's V) indicate the strength of this relationship between the two variables. The phi statistic has a value of 0.235 , so we can conclude that the relationship between these two variables has a medium strength. Thus our H2 hypothesis: The consumers perceive a better quality of the point of sales when the atmospheric factors stimulate their senses was validated also. 


\section{Discussion}

This study replicates and extends previous research on sensory marketing. In line with previous studies, the study shows how consumers react to the atmosphere of restaurants through the cognitive and emotional reactions. The consumer behavior reacts to the emotions and the motives. The internal response (cognitive and/or emotional) of the customers facing the stimuli of the atmosphere is made by a synergy, superposition of the five senses. For a long time, the marketers and psychologists believed that the individual was rational while making a judgment and decision, while the recent studies have shown that the person was making a fast thinking based on the experience and on memories. The sensation and perception are stimulated by the stimuli of the atmosphere and are closely linked: the sensory organs catch information from the atmosphere of the point of sales (sensations). Then these sensations are transmitted through the nervous system to the brain which analyzes it, interpret, and transform it into perceptions. Therefore, the brain transforms these perceptions and sensations into an internal response. This internal response is the reaction of the consumers toward the stimuli of the atmosphere through the emotional or cognitive reaction.

From a theoretical perspective, this study contributes by more highlighting on how sensory marketing works. According to the conducted analysis, the stimuli of the atmosphere influence directly the emotional, behavioral and cognitive response of the individuals. It has been demonstrated the link that can exist between the perception of the quality by the customer and the pleasure he can feel (sensation), between the perception and the sensation. The different components of the sensory stimulations can be selected, combined and improved regarding the evolution of the needs, trends and consumer behavior to adapt it and have a better impact on the experience of the customer.

It was revealed that the cognitive reaction evokes the quality of the point of sales (the process of inference), and the emotional reaction evokes the pleasure felt by the customers through the experience of the sensory marketing. It was identified that the atmospheric factors, such as visual, hearing and olfactory, stimulate the sensory organs of the customers.

Obviously, there are still areas to discover in the sensory marketing field. The understanding of how the senses are connected with the atmosphere, the brain, and the behavior can be a considerable asset for the companies and marketers, to face the rise of the companies using the digital marketing. Furthermore, with the increase of the technologies such as the augmented reality, the virtual helmets or the touch screen in the shops, we can obviously consider a research making a link between these new technologies and the senses of the individuals. And more specifically, how to create a new and rich experience for the consumers at the point of sales through the digital technologies while retaining the influence that can have the senses on the consumer behavior, such as digital tables in the restaurants, or digital noises and scents.

\section{References}

Alpert, M.; Alpert, J. 1989. Background music as an influence in consumer mood and advertising responses, Advances in Consumer Research 16(1): 485-491.

Balaji, M. S.; Raghavan, S.; Jha, S. 2011. Role of tactile and visual inputs in product evaluation: a multisensory perspective, Asia Pacific Journal of Marketing and Logistics 23(4): 513-530. https://doi.org/10.1108/13555851111165066

Bitner, M. J. 1992. Serviscapes: the impact of physical surroundings on customers and employees, Journal of Marketing 56(2): 57-71. https://doi.org/10.2307/1252042

Bruner, G. C. 1990. Music, mood, and marketing, Journal of Marketing 54(4): 94-104. https://doi.org/10.2307/1251762

Dauce, B.; Rieunier, S. 2002. Le marketing sensoriel du point de vente, Recherche Et Applications En Marketing 17(4): 45-65. https://doi.org/10.1177/076737010201700408

Dosquet, F. 2015. Créer du Sens en Marketing. Colombelles. 2eme ed. EMS: Management \& Société.

Hui, M. K.; Dube, L.; Chebat, J. 1997. The impact of music on consumer's reaction to waiting for services, Journal of Retailing 73(1): 87-104. https://doi.org/10.1016/S0022-4359(97)90016-6

Hultén, B. 2011. Sensory marketing: the multi-sensory brand-experience concept, European Business Review 23(3): 256-273. https://doi.org/10.1108/09555341111130245

Kareklas, I.; Brunel, F. F.; Coulter, R. A. 2014. Judgment is not color blind: the impact of automatic color preference on product and advertising preferences, Journal of Consumer Psychology 24(1): 87-95. https://doi.org/10.1016/j.jcps.2013.09.005

Kotler, P. 1973. Atmospherics as a marketing tool, Journal of Retailing 49(4): 48-64.

Krishna, A. 2009. Sensory marketing: research on the sensuality of consumers. New York: Routledge.

Krishna, A. 2012. An integrative review of sensory marketing: engaging the senses to affect perception, judgment and behavior, Journal of Consumer Psychology 22: 332-351. https://doi.org/10.1016/j.jcps.2011.08.003

Krishna, A.; Elder, R. S. 2009. The gist of gustation: an exploration of taste, food, and consumption. Sensory marketing: research on the sensuality of products. New York: Routledge.

Labrecque, L. I.; Patrick, V. M.; Milne, G. R. 2013. The marketers' prismatic palette: a review of color research and future directions, Psychology \& Marketing 30(2): 187-202.

Lemoine, J. F. 2002. Perception de l'Atmosphère du Point de Vente et Réactions Comportementales et Emotionnelles du Consommateur. La Rochelle: Actes du 5ème Colloque Etienne Thil, Université de la Rochelle.

Lindström, M. 2005. Brand sense: build powerful brands through touch, taste, smell, sight, and sound. New York: Free Press. 
Lindström, M. 2010. Brand sense: sensory secrets behind the stuff we buy. New York: Free Press.

Maslow, A. H.; Frager, R.; Cox, R. 1970. Motivation and personality. $2^{\text {nd }}$ ed. New York: Harper \& Row.

Mehrabian, A.; Russell, J. A. 1974. An approach to environmental psychology. Cambridge: M.I.T. Press.

Moch, A.; Moser, G. 1997. La psychologie environnementale en France: perspectives actuelles, Psychologie Française 42(2): $103-106$.

Rieunier, S. 2006. Marketing sensoriel du point de vente: Créer et Gérer l'Ambiance des Lieux Commerciaux. $2^{\text {nd }}$ ed. Paris: Editions Dunod.

Rieunier, S.; Jallais, J. 2013. Marketing sensoriel du point de vente: Créer et gérer l'ambiance des lieux commerciaux. Paris: Dunod.

Saunders, M.; Lewis, P.; Thornhill, A. 2003. Research methods for business students. Harlow, England: Prentice Hall.

Schiffman, S. S.; Sattely-Miller, E. A.; Suggs, M. S.; Graham, B. G. 1995. The effect of environmental odors emanating from commercial swine operations on the mood of nearby residents, Brain Research Bulletin 37(4): 369-375. https://doi.org/10.1016/0361-9230(95)00015-1

Sibéril, P. 1994. L'influence de la Musique sur les Comportements des Acheteurs en rande Surface. Rennes: Thèse de doctorat en sciences de gestion. Université de Rennes 1

Villemure, C.; Slotnick, B. M.; Bushnell, M. C. 2003. Effects of odors on pain perception: deciphering the roles of emotion and attention, Pain 106(1-2): 101-108. https://doi.org/10.1016/S0304-3959(03)00297-5

Yalch, R. F.; Spangenberg, E. R. 2000. The effects of music in a retail setting on real and perceived shopping times, Journal of Business Research 49(2): 139-147. https://doi.org/10.1016/S0148-2963(99)00003-X

Yoo, C.; Park, J.; MacInnis, D. J. 1998. Effects of store characteristics and in-store emotional experiences on store attitude, Journal of Business Research 42(3): 253-263. https://doi.org/10.1016/S0148-2963(97)00122-7 